\title{
Teaching Mathematics by Competency-Based Approach in Preparing Technical Students for Future Professional Working
}

\author{
Gulaiym Zikirova1, Kandalatkhan Turdubaeva², Tolonbai Saadalov³ ${ }^{3}$ Zhypargul Abdullaeva4* (1) \\ ${ }^{1}$ Department of Pedagogics, Osh Technological University, Osh, Kyrgyzstan \\ ${ }^{2}$ Department of Pedagogics, Osh State Pedagogical University, Osh, Kyrgyzstan \\ ${ }^{3}$ Department of Physical and Mathematical Sciences, Osh Technological University, Osh, Kyrgyzstan \\ ${ }^{4}$ Science and Research Department, Osh State University, Osh, Kyrgyzstan \\ Email: *jypar.science@oshsu.kg
}

How to cite this paper: Zikirova, G., Turdubaeva, K., Saadalov, T., \& Abdullaeva, Z. (2021). Teaching Mathematics by Competency-Based Approach in Preparing Technical Students for Future Professional Working. Creative Education, 12, 1783-1791. https://doi.org/10.4236/ce.2021.128135

Received: July 3, 2021

Accepted: August 2, 2021

Published: August 5, 2021

Copyright ( 2021 by author(s) and Scientific Research Publishing Inc. This work is licensed under the Creative Commons Attribution International License (CC BY 4.0).

http://creativecommons.org/licenses/by/4.0/

\section{(c) (i) Open Access}

\begin{abstract}
In this work, the mathematical competence of a future technical specialist is understood as the ability to use their mathematical knowledge in solving practical and theoretical problems that arise in their professional activities, expressing both fundamental mathematical knowledge and unified personal knowledge based on practical skills. The article goals, objectives, content, forms and methods are an integral system aimed at the formation of mathematical competence in University students, determined by the professional and creative training of future specialists. The analysis of ways to achieve the quality of mathematical training, in particular, ways to form mathematical competencies, taking into account the evolution of second- and third-generation standards, shows that these ways have changed significantly. The concept of competence includes a person's possession of appropriate competence, attitude to the subject of activity. Several researchers noted that concept of competence is close to the concept of readiness. Source competence is a set of general methods of action that allow a person to understand the situation, achieve results in personal and professional life in the context of specific professional and social partnerships. Preparation is a complex psychological structure in addition to the necessary knowledge, skills, abilities, and adequate requirements.
\end{abstract}

\section{Keywords}

Competence, Knowledge, Skill, Tasks, Competence Approach, Future Specialist

\section{Introduction}

At the end of the twentieth century, the Europe Council identified among the 
most important political and social competencies related to oral and written communication the competencies associated with the formation emergence of the informative society (Lazareva, 2010). For example, possession of new technologies, the ability to use and to be critical of information and advertising distributed by the media. The concept of competence includes a person's possession of the appropriate competence, his attitude to the subject of activity (Garavan \& McGuire, 2001). Several researchers note that the concept of competence is close to the concept of readiness (Sá \& Serpa, 2018). In fact, a competent professional is an individual who can realize his values and analyze himself, compare himself and others, evaluate, design the future. Competence includes cognitive, practical (functional skills and readiness to carry out activities), axiological (having certain values) and other aspects (components). The competence in scientific scale presenting questions and hypothesis, planning, experimenting and data collection and analyzing, interpreting, and concluding (Arnold et al., 2018). Mathematics facilitate the understanding of various phenomena, be it social reality itself, economic aspects or historical facts, among others (Moreno-Guerrero et al., 2020).

\section{Research Methods}

The structure and content of the mathematical competence of future technical specialists include the following components: axiological (knowledge about mathematical facts, concepts, laws, theories; knowledge about the structure of mathematical activity), epistemological; knowledge about the methods of mathematical knowledge), praxeological (Hoppe, 1993), the ability to self-education, the use of knowledge gained in professional activity, the ability to use the knowledge gained in practice). All of them reflect the requirements for the quality of mathematical training in vocational education.

Preparation, as a complex psychological structure, in addition to the necessary knowledge, skills and abilities, includes not only adequate requirements for professional activities, qualities and abilities of the individual, but also cognitive (understanding professional tasks, assessing their importance, etc., motivational (interest in the profession, striving for success, etc.) and volitional (overcoming doubts, the ability to work on oneself) also include components. The ability of a competent specialist to go beyond the scope of his profession allows defining competence as a higher degree of readiness (Bekboev, 2003).

Rationale in carrying of this study is based on explanation of competence types, mathematical competence formation in higher education, stages and conditions in mathematical competence formation, pedagogical conditions necessary in teaching mathematics, teaching content role, mathematical competence formation in lectures and practical classes and the role of technologies.

\section{Results and Discussions}

\subsection{Competence Types}

Competence is a personality trait (characteristic), which becomes a characteris- 
tic, and the minimum experience in this area (Yoon et al., 2020). Source competence is a set of general (universal) methods of action that allow a person to understand the situation, achieve results in personal and professional life in the context of specific professional and social partnerships. Basic competencies are multifunctional over disciplinary and interdisciplinary, multidimensional and include cognitive components (Zeer \& Symaniuk, 2005). Competence is a general readiness to establish a connection between knowledge and a situation and to form a procedure for solving a problem; some kind of separate requirement for the educational readiness of the student. Educational competence is the student's readiness to use the acquired knowledge, skills and abilities in life or his ability to carry out practical activities.

\subsection{Mathematical Competence Formation in Higher Education}

When preparing mathematics teachers at a pedagogical university, vocational guidance in mathematics is necessary, this was very well studied by O. B. Episheva, A. G. Mordkovich and others (Episheva, 1999). The problem of vocational guidance in mathematics has been studied to some extent in economic universities. Various aspects of vocational education in mathematics have also been studied for many technical specialties.

Following the provisions of the state standard of higher professional education of the third generation in the Kyrgyz Republic, the main didactic conditions for teaching mathematics include contextual learning, mathematics interdisciplinary integration course both with the natural and mathematical cycle disciplines and with the subject-information approach to teaching mathematics and other fundamental his subjects of the cycle. An analysis of the ways to achieve the quality of mathematical training, in particular the ways of forming mathematical competencies, taking into account the evolution of the standards of the second and third generations, showed an essential characteristic of these ways. The evolution of standards makes it possible to prognoses the transition to the use of integrative, integrated approaches aimed at the formation of mathematical competencies in the future, with an increase in the number of basic approaches to teaching mathematics (competency-based, contextual, interdisciplinary, subject-informational). The mathematical competence formation in students depends on a unity of knowledge and experience of application; thus, it becomes necessary in organizing various practices using mathematical knowledge.

\subsection{Stages and Conditions in Mathematical Competence Formation}

Mathematical competence formation in university students is a pedagogical process that takes place in several stages. According to the formation logic in the "Mathematics" academic discipline, the formation of mathematical competence in university students will form in the following stages:

1) Motivational target;

2) Content-activity; 
3) Productive evaluative.

The author of spatial contextual concept teaching A. A. Verbitsky (Verbitsky \& Larionova, 2006) proposed not only the subject but also the social, practice-oriented model content for rising future professional activity in a specialist. Mathematical competence formation effectiveness in university students depends on certain pedagogical conditions.

In our study, we identified the following pedagogical conditions in teaching mathematics (Figure 1): Formation of a stable motivation for teaching mathematics; use of personal developmental techniques; and designing the content of the discipline.

The first condition for the formation of mathematical competencies of university students is the formation of a stable motivation for teaching mathematics. Focusing on this condition as one of the most important features enabling the future specialist to realize the role of mathematics in his professional activity. This problem is especially acute at present, when students, firstly guided by the study of subjects measured by their professional significance and increased competitiveness in the labor market. The choice of the second condition is due to the personal component of the methodological approach to teaching. Developmental techniques used in education are of personality-oriented education importance for potential activities implementation. Developmental education takes into account patterns use, levels and characteristics in personality development. The pedagogical influence during such training overtakes, stimulates, directs and accelerates the trainee's hereditary activities. Work based on the "nearest development zone" of the future specialist will allow more fully determine teachers potential capabilities.

\subsection{Teaching Content Role in Mathematical Competence Formation}

Developing education at the university is a complex chain of subject tasks that cause the student to acquire special knowledge and skills in building a new solution scheme inaccessible to his experience, new ways of acting and thinking. The foreground is not only the actualization of previously acquired knowledge and already established methods of action, but also the promotion of the hypothesis; the idea is to formulate and develop an original plan for solving the problem, to find new independently discovered connections of solution verification and

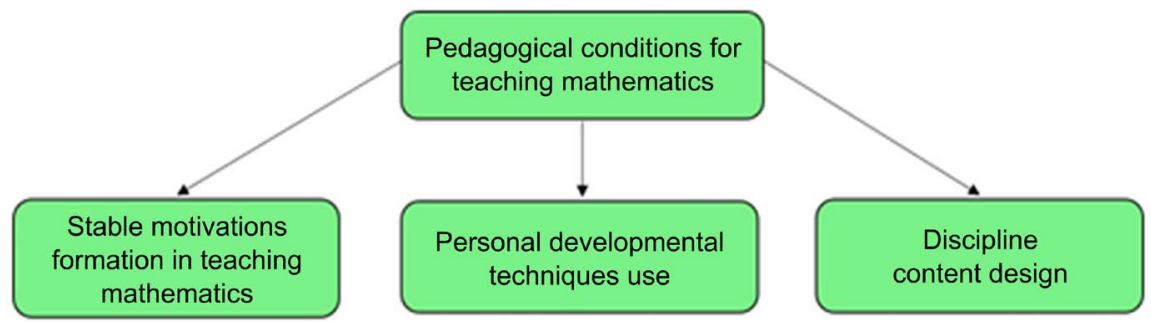

Figure 1. Pedagogical conditions necessary in teaching mathematics. 
search, using the information provided and dependencies between the applicant, known and unknown.

In the process of "searching" for knowledge and creating new ways of performing actions, the future specialist receives specific results in the form and new facts. Thus, already in the learning process, the future specialist rises to new levels of intellectual and personal development. As a third condition, the design of the content of the discipline in the formation of mathematical competencies was chosen.

According to studies adapting the notion of the teaching triangle in mathematics (Pascual et al., 2021), placing teachers education content including the mathematical and didactical elements to be learned by prospective teachers and role of educator about previously occupied knowledge subject to be taught as represented in Figure 2.

An important question when choosing the training content is the question of how to establish a reasonable balance between the fundamental nature and professional orientation of mathematical training, without which it is impossible to achieve its high quality. Various means of vocational guidance training allow you to model the elements of the future professional activity of a specialist. These include, for example, business games. However, the specificity of mathematics is such that the most important means of modeling the mathematical product of future professional activity is the solution of professionally oriented problems.

\subsection{Mathematical Competence Formation in Lectures and Practical Classes}

One of the ways to form the mathematical competence in university students is the development a complex of professionally oriented mathematical problems throughout the entire course of mathematics in combination with traditional mathematical problems in lectures, practical classes and students' independent

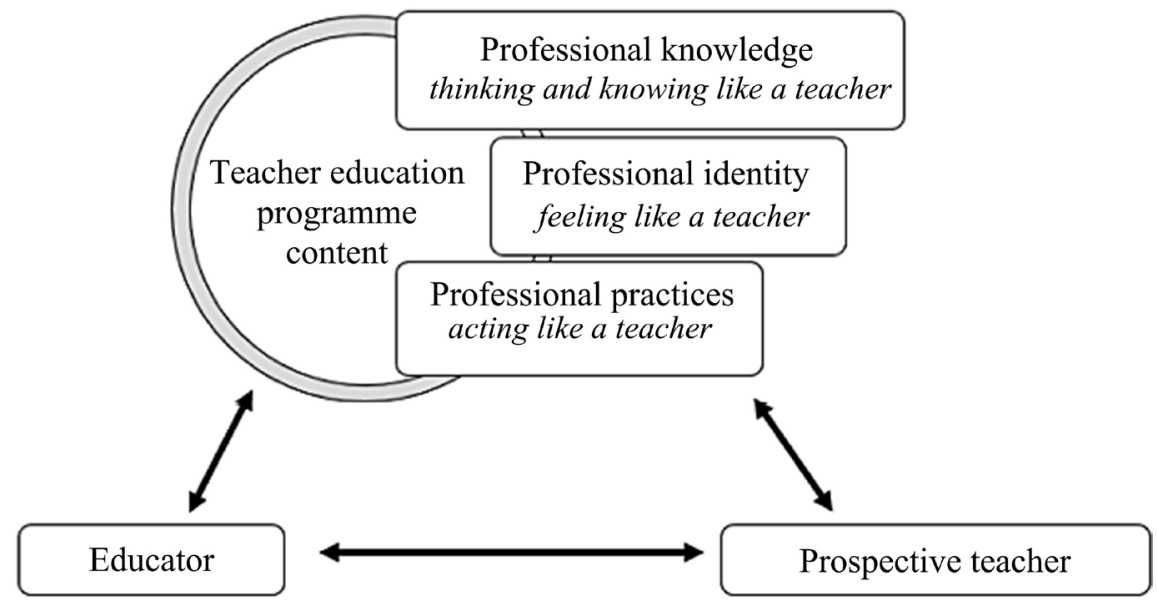

Figure 2. Content of initial mathematics teacher education including educator and prospective teacher roles (represented from Pascual et al., 2021). 
work. Next components in scientific and methodological support for the formation of mathematical competencies in university students were considered. We include traditional teaching methods, information technology and professionally oriented training.

Essentially, traditional teaching is based on the teaching concept. Lectures at higher educational institutions are the main link in the education didactic cycle. Its purpose is to form an approximate basis for the further assimilation of educational material by students.

Currently, the educational materials lecture presentation has both supporters and opponents. However, the practice has shown that refusal to lecture reduces the scientific level of students' training, violates the systematic and uniformity of their work during the semester. Therefore, lectures continue to be the leading form of educational process organization in higher educational institutions. In the process of education at the Higher School, practical classes implemented. They were designed for in-depth study of the discipline, play an important role in the development of students' skills to use the knowledge gained to solve practical problems.

Practical classes are designed to help deepen, expand the knowledge gained at lectures and develop skills for professional activity. Practical classes develop scientific thinking and speech, allow students to test their knowledge, and act as a means of operational feedback.

Along with classroom work, students' independent work is one of the forms of the educational process and is an important part of it. Independence also has an educational value, since it forms independence as a characteristic feature that plays an important role in the structure of the personality of a modern highly qualified specialist.

\subsection{Role of Technologies in Mathematical Competence Formation}

According to the new educational paradigm, every novice specialist, regardless of the specialty and nature of work, must have fundamental knowledge, professional skills and experience in his profile, experience in students creative and research activities to solve new problems, experience in social and evaluative activities.

In a sense, all pedagogical technologies are informational, since the educational process always accompanied by the exchange of information between the teacher and a student. However, education information technologies in the modern sense are pedagogical technologies that use special methods, software and hardware (cinema, audio and video equipment, computers and telecommunication networks) to work with information.

Consequently, information technologies in teaching (Radović et al., 2019) should be understood as applications of information technologies for creating new opportunities for the transfer of knowledge (teacher's activities), knowledge acceptance (student's activities), assessing the quality of teaching and, of course, 
the comprehensive development of the individual in the educational process at the university (Trujillo-Torres et al., 2020).

Computer training allows students to solve a wide range of didactic problems through special computer training programs, expands the training database (electronic libraries, domestic and foreign databases, the Internet), allows you to choose an individual learning pace (adapted computer programs). The practice of using mathematical methods for solving problems is increasingly based on the functionality of software mathematical packages, the most famous of which are Derive, MathCad, Maple, MatLab, Matematica (Ochkov \& Bogomolova, 2015; Anastassiou \& Iatan, 2013). The use of multifunctional software and mathematical support will not only strengthen the implementation of applied direction in mathematical education, but also introduce new opportunities in the professional training of future specialists. From the specialists' point of view of the mathematical competence in solving mathematical problems, it is important to understand the unique capabilities of various tools for implementing various methods in solving and various forms of obtaining results: exact and approximate methods, symbolic (analytical), numerical, graphic results. As it is known, personality is formed and develops primarily in an active form during joint and individual activity.

The main function of subjects in higher educational institutions is teaching methods of solving various problems, focused not only on the knowledge system to form a picture of the world as a whole, but also on the system of professional and educational skills and abilities (Gravemeijer et al., 2017). Formation of high-level mathematical competencies among university students can be achieved only when the student has a clear idea of the need for the acquired knowledge. This can be achieved by solving mathematical problems directly related to future professional activities in the classroom, which are an integral part of professionally oriented teaching of mathematics.

\section{Conclusion}

Based on professionally-oriented teaching in mathematics, we mean the organization of such content of educational material and its assimilation in forms and types of activities that correspond to future specialists system logic to construct a mathematics course and simulate the philosophical and practical tasks for the professional activity. Our developed model of the mathematical competence formation in university students needs to determine the criteria for its effectiveness, which understand its special features and allow us to talk about its achievements. Formation of mathematical competencies in university students determines their advancement to a higher level. In this regard, we have identified the following levels of mathematical competence: low, medium, high.

Practical significance in this work is aimed at the formation of high mathematical competencies of students at the university by involves the creation of a unified system of professional and creative training in future specialists. The 
ways of using mathematical competencies to improve the quality of mathematical knowledge were studied.

\section{Conflicts of Interest}

The authors declare no conflicts of interest regarding the publication of this paper.

\section{References}

Anastassiou, G. A., \& Iatan, I. F. (2013). Intelligent Routines: Solving Mathematical Analysis with Matlab, Mathcad, Mathematica and Maple (582 p). Springer. https://doi.org/10.1007/978-3-642-28475-5

Arnold, J. C., Boone, W. J., Kremer, K., \& Mayer, J. (2018). Assessment of Competencies in Scientific Inquiry through the Application of Rasch Measurement Techniques. Education Sciences, 8, 184. https://doi.org/10.3390/educsci8040184

Bekboev, I. B. (2003). Professional Competence Is the Basis of Quality Pedagogical Work (pp. 65-71). Soros Foundation Kyrgyzstan.

Episheva, O. B. (1999). The Activity Approach as a Theoretical Basis for the Design of a Methodological System for Teaching Mathematics (460 p). Dissertation, Moscow: Tobolsk State Pedagogical Institute named after D.I. Mendeleev.

Garavan, T., \& McGuire, D. (2001). Competencies \& Workplace Learning: Some Reflections on the Rhetoric \& the Reality. Journal of Workplace Learning, 13, 144-164. https://doi.org/10.1108/13665620110391097

Gravemeijer, K., Stephan, M., Julie, C., Lin, F.-L., \& Ohtani, M. (2017). What Mathematics Education May Prepare Students for the Society of the Future? International Journal of Science and Mathematics Education, 15, 105-123. https://doi.org/10.1007/s10763-017-9814-6

Hoppe, H. H. (1993). On Praxeology and the Praxeological Foundation of Epistemology. In H. H. Hoppe (Ed.), The Economics and Ethics of Private Property (pp. 141-164). Springer. https://doi.org/10.1007/978-94-015-8155-4_6

Lazareva, L. I. (2010). The Content of Information Culture of a Graduate of the University of Culture and Arts in the Context of the Third Generation FSES HPE. Bulletin of the Kemerovo State University of Culture and Arts, 12, 105-120.

Moreno-Guerrero, A.-J., Aznar-Díaz, I., Cáceres-Reche, P., \& Alonso-García, S. (2020). E-Learning in the Teaching of Mathematics: An Educational Experience in Adult High School. Mathematics, 8, 840. https://doi.org/10.3390/math8050840

Ochkov, V. F., \& Bogomolova, E. P. (2015). Teaching Mathematics with Mathematical Software. Journal of Humanistic Mathematics, 5, 265-285. https://doi.org/10.5642/jhummath.201501.15

Pascual, M. I., Montes, M., \& Contreras, L. C. (2021). The Pedagogical Knowledge Deployed by a Primary Mathematics Teacher Educator in Teaching Symmetry. Mathematics, 9, 1241. https://doi.org/10.3390/math9111241

Radović, S., Marić, M., \& Passey, D. (2019). Technology Enhancing Mathematics Learning Behaviours: Shifting Learning Goals from "Producing the Right Answer" to "Understanding How to Address Current and Future Mathematical Challenges". Education and Information Technologies, 24, 103-126. https://doi.org/10.1007/s10639-018-9763-x

Sá, M., \& Serpa, S. (2018). Transversal Competences: Their Importance and Learning Processes by Higher Education Students. Education Sciences, 8, 126. 
https://doi.org/10.3390/educsci8030126

Trujillo-Torres, J.-M., Hossein-Mohand, H., Gómez-García, M., Hossein-Mohand, H., \& Cáceres-Reche, M.-P. (2020). Mathematics Teachers' Perceptions of the Introduction of ICT: The Relationship between Motivation and Use in the Teaching Function. Mathematics, 8 , 2158. https://doi.org/10.3390/math8122158

Verbitsky, A. A., \& Larionova, O. G. (2006). Humanization, Competence, Context, Search for the Foundations of Integration. Alma Mater, 5, 19-25.

Yoon, Y., Yan, W., \& Kim, E. (2020). Towards Sustainable Human Resource Development of Convention Project Managers: Job Characteristics and Related Differences in Core Competency. Sustainability, 12, 1-15. https://doi.org/10.3390/su12197898

Zeer, E., \& Symaniuk, E. (2005). Competence-Based Approach to the Modernization of Vocational Education. Higher Education in Russia, 4, 23-30. 